\title{
APROVEITAMENTO DA CASCA E POLPA DE JAMELÃO (Syzygium cumini Lamarck) PARA PRODUÇÃO DE FARINHA COM POTENCIAL ANTIOXIDANTE PARA USO EM BARRA DE MEL CONTENDO DERIVADOS DE MANDIOCA E CEREAL
}

\author{
Samanta Sousa Silva ${ }^{1}$; Sílvia Maria Almeida de Souza ${ }^{2}$ \\ 1. Bolsista PIBIC/FAPESB, Graduanda em Engenharia de Alimentos, Universidade Estadual de Feira de Santana, e-mail: \\ samanta.s.20@hotmail.com \\ 2. Orientadora, Departamento de Tecnologia, Universidade Estadual de Feira de Santana, e-mail: ss_almeida@yahoo.com.br
}

PALAVRAS-CHAVE: Jamelão; Antioxidante; Farinha de resíduo.

\section{INTRODUÇÃO}

O jamelão é conhecido por uma grande variedade de nomes: jambolão, azeitona-do-nordeste, murta, entre outros. Seu nome científico é Syzygium cumini Lamark, uma planta pertencente à família Mirtaceae (Sociedade Brasileira de Diabetes, 2017). O fruto do jambolão se caracteriza por apresentar alta atividade antioxidante e polifenóis (VIZZOTTO, PEREIRA, 2008).

Os polifenóis constituem um grupo heterogêneo, composto de várias classes de substâncias com propriedade antioxidante. Essas substâncias estão presentes em vários alimentos e bebidas (VENDANA, et. al, 2008). Os polifenóis são substâncias com efeito protetor exercido por estes alimentos tem sido atribuído à presença de fitoquímicos com ação antioxidante. Os compostos fenólicos são os maiores responsáveis pela atividade antioxidante em frutos (SOUZA; SILVA, 2012).

Devido ao alto índice de desperdício de partes das frutas, percebe-se a necessidade de elaboração de produtos a partir de partes não usualmente utilizadas, como a casca das frutas, a citar farinha obtida a partir do resíduo de frutas. Para isso escolheu-se o jamelão, por ser uma fruta comumente encontrada na região, e que ainda possui uma carência no seu aproveitamento. Além disso, a fruta tem safra anual, dezembro a março, o seu tempo de amadurecimento após a colheita é de 1 a 2 dias, o que o caracteriza em um produto altamente perecível, necessitando de congelamento para a preservação de suas características. Fazendose necessário o uso de técnicas para elaboração de produtos que permita o consumo da fruta durante todo o ano.

Este trabalho teve como objetivo o desenvolvimento de farinha de resíduo oriundo de jamelão através do estudo da cinética de secagem do extrato da fruta e a posterior quantificação do teor de antioxidante da farinha.

\section{METODOLOGIA}

As atividades foram desenvolvidas no laboratório de Processamento de Alimentos do Departamento de Tecnologia na Universidade Estadual de Feira de Santana (UEFS). As frutas foram colhidas na UEFS e em fazendas na cidade de Amélia Rodrigues nas safras de março a dezembro de 2016 , higienizados e congelados a $-18{ }^{\circ} \mathrm{C}$. Antes do despolpamento as frutas foram descongeladas na geladeira a $5^{\circ} \mathrm{C}$ por 14 horas. 
O preparo do resíduo da fruta utilizado na cinética de secagem e preparo da farinha consistiu no despolpamento da fruta, seguido por trituração da polpa em liquidificador em velocidade baixa por 30 segundos com água na proporção 1:1, a solução foi filtrada em malha fina para extração da água. A cinética de secagem foi realizada em triplicata nas temperaturas de 70, 60 e $50{ }^{\circ} \mathrm{C}$, em estufa com circulação de ar. Em cada amostra foram utilizadas 10 gramas de extrato despostos em camada de $2 \mathrm{~mm}$. Nas duas horas iniciais foram realizadas pesagens em intervalos de 15 minutos, nas horas seguintes as pesagens foram realizadas em intervalos de 2 horas até peso constante. As razões de água e a curva da razão de água em função do tempo foi construída a partir da perda de massa durante a secagem, considerando apenas perda de água ao longo da secagem. O cálculo da razão de água foi calculado pela Equação 01.

Onde,

$$
R U=\left(X-X_{e}\right) /\left(X_{i}-X_{e}\right) \quad \text { Equação (01) }
$$

RU: Razão de água (adimensional)

$\mathrm{X}$ : Teor de água no resíduo (b.s.)

$\mathrm{X}_{\mathrm{e}}$ : Teor de água de equilíbrio do resíduo (b.s.)

$\mathrm{X}_{\mathrm{i}}$ : Teor de água inicial do resíduo (b.s.)

Para o preparo da farinha do resíduo foi preparado da mesma maneira para a cinética de secagem, e a secagem do resíduo foi realizada a $60{ }^{\circ} \mathrm{C}$ em estufa com circulação de ar em placa de Petri, até alcançar $5 \%$ b.s. (base seca), seguida por trituração em liquidificar até obtenção de granulometria própria do processo de fabricação, porém dentro dos padrões de classificação da legislação para farinha de mandioca.

As análises de fenóis totais foram feitas pelo método de Folin-Ciocalteau no resíduo, antes da secagem, e na farinha para avaliação da perda de fenóis no processo de secagem. As amostras foram condicionadas em embalagens recobertas com papel alumínio até o início da análise para evitar a interferência da luz.

Análises de umidade, cinzas, lipídios e proteínas foram realizadas na farinha conforme a metodologia descrita pelo Instituto Adolfo Lutz (2008)

\section{RESULTADOS E DISCUSSÃO}

O resíduo do jamelão apresentou umidade inicial de $81,80 \%$ b.u. (base úmida) e $452,02 \%$ b.s. (base seca), a secagem foi realizada até atingir umidade de $0,02 \%$ b.u e $0,16 \%$ b.s. O comportamento do extrato de jamelão durante a secagem está ilustrado no gráfico abaixo ilustrado pela Figura 1.

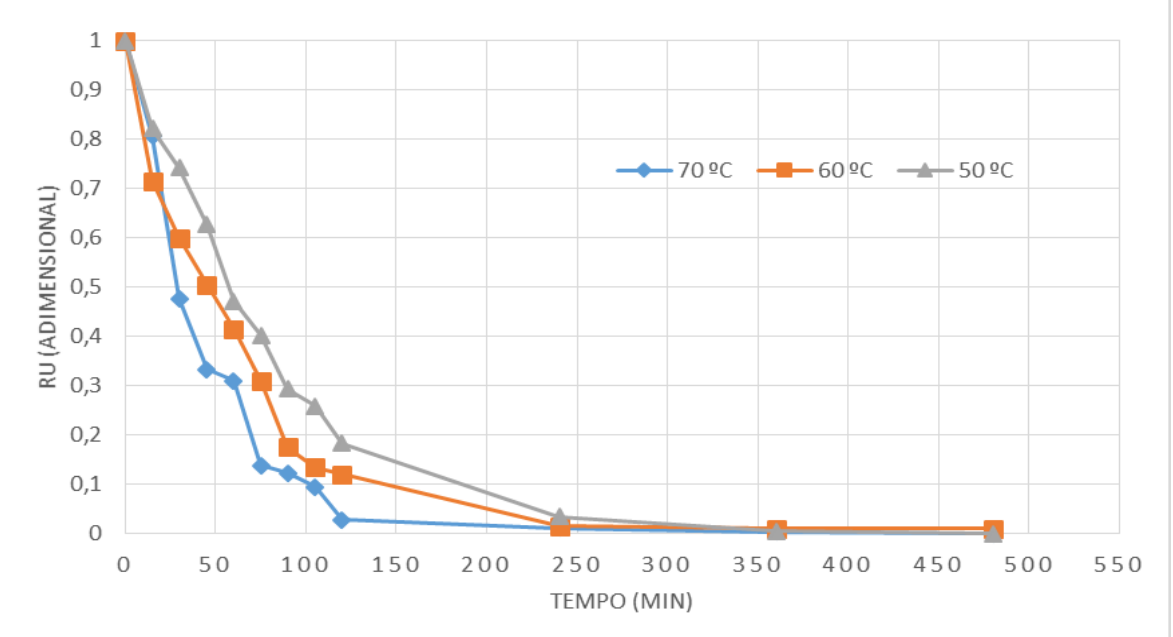

Figura 1: Cinética de secagem do extrato de jamelão 
A análise da Figura 1 demonstra o comportamento similar e contínuo da perda de água ao longo da secagem. Pela análise do gráfico pode-se observar que o aumento da temperatura implica na taxa de redução do teor de água da amostra em razão do maior gradiente de umidade entre o produto e o ar, consequentemente o tempo de secagem é reduzido, como também foi analisado por Santos, et. al (2012) na secagem de grãos de urucum, Ferreira e Pena (2010) com a secagem da casca do maracujá e Silva, et. al (2016) com o estudo da secagem da polpa de carambola. A umidade de equilíbrio do produto foi alcançada em 240 minutos para secagem a $70{ }^{\circ} \mathrm{C}, 540$ minutos para secagem a $60{ }^{\circ} \mathrm{C}$ e 120 minutos para secagem a $50{ }^{\circ} \mathrm{C}$.

A secagem da farinha foi realizada a $60{ }^{\circ} \mathrm{C}$ em 430 minutos, o extrato da fruta possuía umidade inicial $74,8 \%$ b.u. e a secagem procedeu até atingir $5 \%$ b.s. O rendimento da farinha foi de $2,77 \%$ em relação a fruta com caroço e $5,12 \%$ em relação a fruta sem caroço.

A composição centesimal de frutas depende da região produzida, condições climáticas, fertilização e época de plantio. Barcia (2009) estudou frutos de jamelão com $83 \%$ de umidade, 0,35\% de cinzas, $0,91 \%$ de proteína, $0,42 \%$ de fibras, $24,5 \%$ de açúcares redutores e $51,4 \%$ de açúcares totais. Em complemento Lagos, Gomes e Silva (2006) caracterizou frutos com $87,75 \%$ de umidade, $0,34 \%$ de cinzas, $0,30 \%$ de lipídeos e $0,67 \%$ de proteínas. O processo de secagem visa a redução da umidade para a extensão da vida de prateleira do produto, através da disponibilidade da água livre no alimento, funcionando como barreira microbiológica tornando o ambiente menos propício ao desenvolvimento microbiano. A secagem não implica em perdas consideráveis na composição centesimal de frutas, a caracterização físico-química da farinha de jamelão está descrita na Tabela 1.

Tabela 1. Caracterização físico-química da farinha de jamelão

\begin{tabular}{cc}
\hline Determinação & $\begin{array}{c}\text { Média } \\
(\mathbf{g} / \mathbf{1 0 0 g})\end{array}$ \\
\hline Umidade (b.s.) & $10,06 \pm 0,12$ \\
Cinzas & $0,41 \pm 0,08$ \\
Lipídeos & $0,21 \pm 0,06$ \\
Proteínas & $0,80 \pm 0,09$ \\
\hline
\end{tabular}

O teor de fenóis totais foi quantificado pela extração em solução hidroetanólica pelo método de Folin-Ciocalteau em amostras antes da secagem e na farinha, os resultados obtidos foram 351,60 e 302,56 mg/100 g de fenóis, respectivamente. Rezende (2010), estudou o teor de fenóis totais em frutas consumidas na Bahia e determinou a concentração de fenóis em polpas congeladas, usando solução extratora de hidroetanólica, de 1405,79 mg/100 g de jabuticaba, $427,12 \mathrm{mg} / 100 \mathrm{~g}$ de seriguela, 400,96 mg/100 g de cajá e 52,72 mg/100 g de umbu. Kuskoski, et. al (2006) determinou a concentração, usando solução etanólica, de polifenóis totais de 229,6 mg/100 g de jambolão, 117,1 mg/100 g de polpa de uva, 580,1 mg/100 g de polpa de acerola e 20,5 mg/100 g de polpa de cupuaçu. A diferença apresentada no teor de fenóis, na torta de resíduo, antes e depois da secagem sugere que o calor influenciou na concentração do mesmo, indicando redução na concentração em decorrência da degradação dos fenóis ocasionada ao longo do tempo de secagem $\left(60{ }^{0} \mathrm{C}\right.$ e $\left.430 \mathrm{~min}\right)$. Contudo, a redução foi de $13,95 \%$, permanecendo a farinha de resíduo de jamelão uma boa fonte de fenóis.

\section{CONCLUSÃO}

O jamelão é uma fruta que ainda não possui suas propriedades bromatológicas conhecidas pela população, em especial seu poder antioxidante, sendo dificultado, especialmente, pelo curto período de safra. A secagem da torta do jamelão para a produção da farinha não 
implicou em perdas nutricionais significativas, dessa maneira, a farinha de jamelão permite o enriquecimento nutricional da alimentação. Assim, a farinha de resíduo apresentou-se como uma alternativa viável para o consumo de jamelão ao longo de todo o ano.

\section{REFERÊNCIAS}

BARCIA, M. T. Composição Centesimal e de Fitoquímicos em Jambolão (Syzygium cumini). Dissertação de pós-graduação, Universidade Federal de Pelotas. 2009. 79 p.

FERREIRA, M. de F. P.; PENA, R. de S. Estudo da secagem da casca do maracujá amarelo. Revista Brasileira de Produtos Agroindustriais, Campina Grande, v.12, n.1, p.15-28, 2010 GONDIM, J. A. M.; MOURA, M de F. V.; DANTAS, A. S.; MEDEIROS, R. L. S.;

SANTOS, K. M. Composição centesimal e de minerais em cascas de frutas. Revista Ciência e Tecnologia de Alimentos Campinas, 25 (4): 825-827, out-dez. 2005. 6 p.

INSTITUTO ADOLFO LUTZ - IAL. Normas analíticas do Instituto Adolfo Lutz: Métodos químicos e físicos de análise de alimentos. 4.ed. Brasília: IAL, 2005, 1018 p. (Série A Normas e Manuais Técnicos).

KUSKOSKI, E. M.; AUSERO, A. G.; MORALES, M. T; FETT, R. Frutos tropicais silvestres e polpas de frutas congeladas: atividade antioxidante, polifenóis e antocianinas. Revista Ciência Rural, Santa Maria, v. 36, n. 4, p. 1283-1287, jul-ago, 2006. 5 p.

LAGOS, E. S.; GOMES, E.; SILVA, R. da. Produção de Geléia de Jambolão (Syzygium Cumini Lamarck): Processamento, Parâmetros Físico - Químicos e Avaliação Sensorial. Revista Ciência Tecnologia de Alimentos, Campinas, 26(4): 847-852, out-dez. 2006. 6 p. MELONI, P. L. S. Desidratação de frutas e hortaliças. Fortaleza: Instituto Frutal, 2003. 87p. REZENDE, L. C. de. Avaliação da atividade antioxidante e composição química de seis frutas tropicais consumidas na Bahia. Tese pós-graduação, Universidade Federal da Bahia, 2010, 118 p.

SANTOS, D. da C.; QUEIROZ, A. J. de M.; FIGUERÊDO, R. M. F. de; OLIVEIRA, E. N. A. de. Cinética de secagem de farinha de grãos residuais de urucum. Revista Brasileira de Engenharia Agrícola e Ambiental. V. 17, n. 2, p. 223-231, 2013

SILVA, R. B. da; SILVA, F. S. da; PORTA, A. G.; ALVES, A. P. Estudo da cinética de secagem de polpa de carambola. Revista Brasileira de Tecnologia Agroindustrial, Ponta Grossa, v. 10, n. 2, p. 2069-2080, jul.- dez. 2016.

SOUZA, M. C. C. de; SILVA, M. V. L. Determinação da Capacidade Antioxidante de Frutas Típicas do Semiárido. XVI Jornada de Iniciação Científica, Salvador. 2012. 2 p.

VENDANA, M. I. S.; ZIEMER, C.; MIGUEL, O. G.; PORTELLA, A. C.; CANDIDO, L. M. B. Efeito do processamento na atividade antioxidante da uva. Revista Alimentos e Nutrição, Araraquara, v. 19, n. 2, p. 159-165, abr-jun. 2008. 7 p.

VIZZOTTO, M.; PEREIRA, M. C. Caracterização das propriedades funcionais do jambolão. Pelotas: Embrapa Clima Temperado, 2008. 27 p. 